\title{
THE TEACHING OF AEROSPACE VEHICLE DESIGN AT CRANFIELD UNIVERSITY WITH PARTICULAR REFERENCE TO THE GROUP DESIGN PROJECT.
}

\author{
P.J.Stocking \\ Department of Aerospace Engineering, School of Engineering, \\ Cranfield University, Cranfield, Bedford MK43 OAL, UK \\ Email: p.stocking@cranfield.ac.uk
}

Submitted to the Journal of Aerospace Engineering, $31^{\text {st }}$ July 2006

\begin{abstract}
Over the years the Aircraft Design course at Cranfield has evolved into the postgraduate master's programme in Aerospace Vehicle Design that we have today. One of the unique features of the course is the extensive group design project, which has played a fundamental part in aircraft design education right from 1948 up to the current day. The success of the course, and the student experience, depends on the success of the group design project. The philosophy of the role of the group design project in the teaching of aircraft design is discussed in detail in this paper. Some examples are presented of recent subject aircraft along with some novel features of these designs.
\end{abstract}

KEYWORDS: Aircraft Design, Aerospace Vehicle Design, Group Design Project, Problem Based Learning, Design Education

\section{INTRODUCTION}

The teaching of Aircraft Design at Cranfield has its roots in the formation of the College of Aeronautics back in 1946. Aircraft Design was one of the original foundation courses, along with Aerodynamics and Aircraft Propulsion. The first course in Aircraft Design began in October 1946. This was a two year course, and students graduated with a Diploma of the College of Aeronautics.

It was intended that 'training will be of a kind different from that given at existing institutions. For instance, instruction will be given in practical design of aircraft, including their power plants and instrument equipment' [1]. Indeed the emphasis was on the application of the results of theory, experiment and calculation to the practical design of aircraft structures. Students were expected to work independently on a research project, and also to work together on the structural design and stress analysis of an aircraft component. Drawing Office practice was emphasised throughout the course, and students produced detailed pencil and paper engineering drawings of their component designs.

In the late 1960's when the Cranfield Institute of Technology was established, the course changed from a Diploma to an MSc in Aircraft Design. Then in the mid 1980's following a group design project involving a 'shuttle' type spacecraft, the title of the course was changed to what we have today, the MSc in Aerospace Vehicle Design.

Over the more recent years, the course has been broadened in content 
and now appeals to a much wider student audience. The strong emphasis on aircraft structural design and stress analysis still remains, but now students are also involved in systems design such as electrical, fuel and Avionics, and more recently operational aspects such as maintenance and reliability. This multi disciplinary design activity brings with it the added dimension of airframe systems integration. So exactly what is the best way to teach students about the modern complexities of aircraft design? One approach is through the use of group project work.

\section{THE AEROSPACE VEHICLE DESIGN MSc PROGRAMME STRUCTURE}

\subsection{COURSE AIMS}

Within the Aerospace Vehicle Design course, the philosophy is that knowledge, understanding and skills necessary for the practice of aircraft design are best acquired through interdisciplinary teaching and demanding application, rather than through a disjointed series of individually assessed modules. Hence as a consequence, the course has offered for many years full integration of engineering technology and aircraft design practice. Integrated teaching is, of course, more difficult to organise, and needs to be kept under constant review, but students who have completed the course have achieved levels of attainment which makes the effort worthwhile. As part of the continuous review process student opinion is an important element and great care is taken to ensure that the teaching given is appropriate to the students needs.

The aims of the course are

- To build upon the students' knowledge gained in their first degree to enable them to enter a wide range of aerospace and related activities concerned with the design of flying vehicles such as aircraft, missiles, airships and spacecraft. This helps to ensure that the student is of immediate use to their employer and has sufficient breadth of understanding of multidiscipline design to position them for accelerated career progression.

- To provide teaching that integrates the range of disciplines required by modern Aircraft Design, e.g. Structural Design and Analysis, Aircraft Systems Design, Propulsion, Flight Performance, Aspects of Manufacture, operations and cost.

- To provide the opportunity for students to be immersed in a Virtual Industrial Environment giving them 'hands-on' experience of interacting with and working on an Aircraft Design Project.

- To provide students with the opportunity of completing a piece of individual research.

\subsection{INTENDED LEARNING OUTCOMES}

In terms of knowledge and understanding, students who successfully complete the course will be able to demonstrate

- The implementation of the principles of aerospace design related to aircraft performance, structures and systems.

- An understanding of the up-to-date aircraft design methods and techniques used in the aerospace industry.

- An application of airworthiness requirements and design standards used in the design and development of aerospace vehicle structures and systems.

- An understanding of the use of modern tools to facilitate the 
solution to aircraft engineering problems, including the use and application of information systems, modern computer systems and software packages such as CATIA and NASTRAN/PATRAN.

- The selection of suitable candidate materials, both metallic and composites, for application to aerospace vehicle structures.

- A working knowledge of stress analysis and fatigue and fracture (damage tolerance), and their application to aerospace vehicle structures.

- A working knowledge of airframe systems, their role, design and integration.

- An understanding of the considerations necessary when selecting aircraft mechanical (power) systems and fuels, and their effect on the aircraft as a whole.

- A working knowledge of the fundamentals of aerodynamics and loading actions as applied to an aircraft vehicle.

- The ability to undertake independent research on a subject relevant to aerospace vehicle design.

Just as important today is an engineers' personal skills, such as being able to work as part of a team, and being able to present and defend design solutions to a variety of audiences. Hence the course also aims to develop these personal skills and upon successful completion the student will be able to

- Communicate effectively, both orally and in writing, and be able to work and communicate in a group environment.

- Plan, execute and manage projects.

- Undertake and manage research studies and have the ability to undertake independent learning.
- Apply and select appropriate analysis and design tools to solve engineering design problems.

- Present clearly, proposals and results in written and oral format to a variety of audiences.

- Undertake a critical appraisal of technical literature.

- Demonstrate ability in practical approaches to solving design problems.

- Critically evaluate data.

- Discuss their work and relate it to the work of others.

- Work effectively under time pressure.

- Seek employment with confidence and to make an immediate contribution to the work of an employer.

\subsection{TEACHING AND LEARNING STRATEGY}

The effective teaching of engineering design is achieved through the practical 'hands-on' approach of learning through the experience of doing.

The Aerospace Vehicle Design MSc is designed around the group design project. It is the application of the taught knowledge to the group design project which challenges and enhances the students' knowledge and understanding and develops their independent learning and problem solving skills. This approach avoids over reliance on teacher centred learning (Fig 1).

The transfer of knowledge, the understanding and application are also achieved through

- Lectures.

- Case studies.

- Group exercises.

- Computer based demonstrations.

- Visiting lecturers from industry specialists. 
- Visits to industry including both aircraft manufacturers and maintenance organisations.

\subsection{ASSESSMENT STRATEGY}

The assessment strategy must be consistent with the teaching and learning strategy. The assessments therefore are designed around problem solving skills, and hence much more emphasis is placed on thesis assessment rather than knowledge recall assessment such as examinations.

The Aerospace Vehicle Design MSc is unique in that students are required to submit two theses for assessment, one thesis for the group design project, the other thesis for the individual research project. The group design project thesis is weighted at $50 \%$ whilst the individual research project thesis is weighted at $40 \%$.

In addition, students are required to sit two formal examinations, one in the Design and Analysis of Composite Structures, and one in Airframe Systems. These two examinations have been carefully chosen to ensure a broad based assessment in aircraft design. These two examinations together are weighted at $10 \%$.

\subsection{LECTURE MODULES}

There exists a portfolio of both mandatory and optional subjects which form the building blocks of knowledge that the students require for the group design project and the individual research project. The modules are sequenced to provide the required knowledge and skills in the right order for application to the group design project. include

Mandatory lecture modules

- Aircraft loading actions.

- Aerodynamics, Performance and Stability and Control.
- Airframe Systems.

- Detail Stress Analysis.

- Design and Analysis of Composite Structures.

- Fatigue, Fracture and Damage Tolerance.

- Aeroelasticity.

- Design for Manufacture and Operation.

- Initial Aircraft Design.

include

Optional lecture modules

- CAD (CATIA).

- Finite Element Methods - Static and Dynamic Analysis of Structures (NASTRAN / PATRAN).

- Structural Stability.

- Aircraft Accident Investigation.

- Structural Crashworthiness.

- Avionic Systems Design.

- Aircraft Powerplant Installation.

Through a combination of the mandatory modules, and a selection of the optional modules, students must accumulate a minimum total of 240 class contact hours.

\subsection{THE INDIVIDUAL RESEARCH PROJECT}

The individual research project aims to provide the training necessary for individual application to research. A topic is chosen by the student in conjunction with either the students' sponsor, a requirement from industry, or from Cranfield University, and will be supervised by Cranfield staff. The project may contain an element of manufacture and test, depending on the topic selected.

The individual research project allows the student to develop their independent learning ability so as to advance their knowledge and understanding in a specific research area. The research project also allows 
the student to develop their ability to critically evaluate current research, data or methodologies. Transferable skills such as self direction to problem solving, planning, managing and executing work effectively as an individual, communication and presentational skills both orally and in writing are also developed through the individual research project.

The following is a short list of topics selected because of their connections with industrial sponsors

- Measurement and Prediction of Corrosion Prevention Compound Performance using Corrosion Sensors.

- Composite Panel Cut-Out Effect and Edge Reinforcement Design.

- The Effect of Scarf Angle on the Quality of Composite Laminate Repair.

- Wing Structural Design for a Distributed Propulsion System.

- Estimation of Fatigue Crack Initiation Life of Notched Samples.

- Modelling of Helicopter Structural Crash Behaviour.

- Structural Optimisation of Racing Catamarans.

- Investigation of the Transformation of Defects in Aircraft Structures into Fatigue Cracks.

Current topics of green interest to the aviation industry include

- Design Study of Environmentally Benign Airliners and Cargo Aircraft.

- Conceptual Design of Silent Airliners.

\subsection{THE GROUP DESIGN PROJECT}

\subsection{AN HISTORICAL} PERSPECTIVE [2]

Early records indicate that the very first students in academic year
1947 / 1948 undertook two group project aircraft conceptual design studies rather than detail design investigations. These studies then formed the basis for the group design project of the second student entry in academic year $1948 / 1949$.

In those early years the aim of the group project was for the student group to undertake the structural and mechanical design of the subject aircraft. Each student was expected to produce a set of around ten engineering drawings, covering in reasonable detail the main problem areas of a component backed up by stress calculations to support the design data. Only a very brief report was required, the drawings being the main form of communication of the design.

Later with the introduction of the MSc, it became necessary for each student to present their work in the form of a formal thesis, and hence the descriptive content became much more extensive and important. The thesis was expected to cover the design process and design evolution, alternative concepts considered, and discussions on the final design solution. Supporting analyses and stress calculations were relegated to an appendix.

\subsection{THE GROUP DESIGN PROJECT TODAY}

Although group projects are a frequent feature of many other aeronautical courses, they are almost invariably concerned with the derivation of the outline of an aircraft from a given specification that is the conceptual design phase.

The Aerospace Vehicle Design course differs in that the starting point for the group project is a fully defined concept aircraft. The conceptual design phase is undertaken by a member of the Cranfield staff before the course 
begins. Hence the task of the students is to take the concept aircraft through to the preliminary and detail design phases (Fig 2) with the end aim of producing detailed engineering drawings and system architecture validated through theoretical analysis.

The aim of the Group Design Project is to provide the students with a virtual industrial environment through which the knowledge and skills acquired from the taught component can be applied to a real aircraft design project. Each student is given the responsibility for the detailed design of a significant part of the aircraft, for example, forward fuselage, wing, or fuel system. Hence students have the opportunity of working together yet have to carry out individual tasks upon which the whole team is dependent.

The subject aircraft are chosen to represent current international aerospace interests. Over the years there have been approximately equal numbers of military and civil designs.

The group design project is both real and engaging. It places the student group in a professional role as aerospace design engineers. The subject aircraft invariably contains new and novel features and therefore presents new challenging problems every year. These represent challenges to the teaching staff as much as to the students, and thus assist in breaking down any barriers between students and staff. Hence generally the relations between teaching staff and students are good. The additional common objective for the students generated by the group design project, gives rise to an enjoyable, self motivated and enthusiastic student participation in all aspects of the course.

\subsection{AN EXAMPLE OF PROBLEM BASED LEARNING}

Problem based learning (PBL) is about learning through solving real relevant problems. Students have to actively acquire the processes, knowledge and skills they need in order to solve the problem. Students are learning to learn.

PBL is widely used in the training of medical students. 'PBL was popularised in the 1960's as a result of research by Barrows into the reasoning abilities of medical students. This research stemmed from a desire to help medical students develop the ability to relate their knowledge to the problems with which the patients presented, something they found that few medical students could do well' [3]

The group design project is an example of PBL. The group project is a real and engaging problem. The students have to work as a team to manage the design process. The course curriculum is organised around the group project problem (Fig 3). The students are presented with the problem before they have the skills and knowledge to solve it. The students have to actively acquire the knowledge they need to solve the problem, and then apply it.

For academic year 2005 - 2006 peer review has been introduced as an element of the group project assessment. Peer review has shown to be a good fit with PBL because "it emphasises the cooperative nature of the PBL environment' [3]. It gives the students the opportunity to reward (or otherwise!) their peers according to effort and contribution made to the group project.

PBL through the group design project has shown to produce motivated students, develops a deeper understanding of the subject, encourages independent and team learning, and develops skills such as problem solving, team working and communication. 


\subsection{A VIRTUAL INDUSTRIAL ENVIRONMENT}

In order for the group project to work effectively, the design problem has to be real and engaging. To achieve this the group design project is operated as a virtual industrial environment.

To ensure that the virtual industrial environment is authentic, industry standard tools are used such as NASTRAN, PATRAN and CATIA. Industry standard resources such as ESDU, MMPDS, MIL-STD, JAR, DEF-STAN and CS data sheets are all used as reference sources for the design process.

The student group is organised as shown in Fig 4. Student sub groups are formed in structural design and systems design. In addition, a subgroup is formed to undertake tasks associated with project monitoring, CAD configuration control, wind tunnel model manufacture and wind tunnel testing.

Weekly group project meetings are held and chaired by the Head of the Aerospace Engineering Group (who acts as Chief Engineer), supported by five additional University staff members and a retired Chief Designer from Industry acting as an external consultant . At each meeting, each individual student is expected to give a weekly progress report concentrating on design issued to be solved. Both qualitative and quantitative evidence is expected from the student with staff members providing guidance and feedback as appropriate.

A minimum of two industrial visits are made each year. These visits are intended to provide the students with the opportunity to view complete aircraft or aircraft components up close, to question industrial specialists, thus enhancing their knowledge and understanding of detail design.
The students collectively present a preliminary design review about their group project work to the external examiners.

Upon completion of the group project, the students give a full one day critical design review presentation to an invited audience of over 100 senior guests from industry, academia and the military.

\subsection{SOME RECENT EXAMPLES OF GROUP PROJECT AIRCRAFT}

\subsection{THE F02 CIVIL FREIGHT AIRCRAFT [4]}

Conversion of military transport aircraft to the civil freight role is not so common, but examples do include some 120 Hercules C-130's re-designated as L-100's. In this light, it was decided to explore the feasibility of adapting the AIRBUS A400M military transport to the civil role. This would give a significant increase in the capacity over the L-100's (20 tonne) and would result in an aircraft in the AIRBUS A310 / Boeing 767 category but with the possibility of using new technology to reduce operating costs. Such an aircraft, designated F02 is shown in Fig 5.

The F02 was designed to the airworthiness requirements of JAR 25 and has a maximum design payload of 38 tonne to be carried over a nominal range of $2000 \mathrm{~nm}$ (with reserves). The aircraft is designed to cruise at M0.7 at $10 \mathrm{~km}$ altitude. The MTOW is 116.5 tonne. The aircraft is powered by four Rolls Royce BR 715-58 turbofan engines.

The wing has a span of $47.4 \mathrm{~m}$ and an aspect ratio of 11 . The overall length of the fuselage is $41 \mathrm{~m}$ with a diameter of $5 \mathrm{~m}$. The length of the freight hold is $28 \mathrm{~m}$. 


\subsection{THE U3 JOINT SERVICES UNMANNED COMBAT AIR SYSTEM [5]}

The preferred means of waging war has evolved out of all recognition compared to that of the last 30 years.

There are ever increasing demands for increased military precision to prevent civilian casualties, and also casualties to friendly forces.

There are also demands for higher performance with reduced costs. The drive for integration between the armed forces has seen the development of aircraft intended for service with all main branches of the military. This requirement will need to be addressed in the design of all future aircraft.

One novel concept appears to offer a solution to all these challenges. The Uninhabited Tactical Aircraft (UTA) or Unmanned Combat Air Vehicle (UCAV) which is seen as a new class of aircraft that is complementary to the existing or planned manned fleet. The ability of this aircraft to effectively perform Strike and Suppression of Enemy Air Defences (SEAD) missions whilst achieving low life cycle costs (LCC) has made it a serious contender for UK programs such as the Future Offensive Air System (FOAS) or possibly part of such a system. Such an aircraft designated U3 is shown on Fig 6.

The U3 was designed to the airworthiness requirements of DEFSTAN 00970 where appropriate, with an airframe life of $6000 \mathrm{hrs}$. Three aircraft variants exist

- Conventional take off and landing.

- Short take off and vertical landing.

- Carrier version.

With a level flight performance of M0.85 at 250ft, and a ceiling altitude greater than $40,000 \mathrm{ft}$, the structural design requirements were $+7.5 \mathrm{~g}$ to $-3.5 \mathrm{~g}$ with a MTOW of 11.8 tonne.

The wing has a span of $10 \mathrm{~m}$ and an aspect ratio of 2.85 . The aircraft is powered by an up rated version of the General Electric F404-402. Vertical landing is achieved by a lift fan mounted in the forward fuselage, a swivel nozzle in the aft fuselage, and roll posts out in the wings.

With the increasing demands of payload range requirements of future UCAV's, it was decided to attempt to make the internal weapons carriage consistent with that of the Joint Strike Fighter (JSF). The design driver was therefore two JDAM's. Stealth required the bomb bay doors to be on top of the wing, which lead to the novel feature of the aircraft having to invert to drop its bombs.

One further novel feature of this aircraft was the lack of a vertical control surface. Hence yaw control was achieved by Inlaid Control Effectors (ICE) mounted on the upper and lower surface of each wing. When working in unison, they provide yaw control, and when working differentially, they provide increased roll authority at low speed.

\subsection{THE M4 MARS ATMOSPHERIC FLIGHT VEHICLE [6]}

The planet MARS has been a source of fascination for many hundreds of years. Many robotic probes have been sent to MARS, some orbiters, some landers, with the intent to learn more about our neighbour. If we are ever to send manned expeditions to MARS then we need extensive surveys from robotic scouting missions.

Missions to MARS are challenging feats of engineering. On average, over half have failed. Modern MARS probes generally fit into one of two classes - Orbiters or landers. The 
former are able to survey the entire planet with a range of sensors from high altitude. The latter are able to obtain a more detailed survey of a very limited area.

There currently exists a gap in the available altitude range that could be filled by an atmospheric flight vehicle. From this intermediate vantage point it would be possible to survey regions (10's to 100's of square kilometres) from low altitude. This would allow higher resolution mapping of such things as the residual magnetic field, and the geological strata of the sides of MARS largest canyon "Valles Marineris' which is over $4000 \mathrm{Km}$ in length and up to $8 \mathrm{Km}$ high. Such a vehicle designated M4 was designed to fulfil this mission and is shown on Fig 7.

Launched from Earth on a Delta II rocket, the M4 is folded up inside an Aeroshell capsule. Upon arrival at MARS the Aeroshell is slowed by parachute. Following the heat shield release, the M4 then departs from the Aeroshell, its wings and tail boom open out, and flight begins.

The M4 is designed to carry a $10 \mathrm{~kg}$ surveillance payload at an altitude of $6 \mathrm{~km}$. It has a range of up to $620 \mathrm{~km}$ and an endurance of up to 75 minutes, after which the vehicle crashes into the Martian surface.

The M4 has an overall length of $4.4 \mathrm{~m}$, a wing span of $6.18 \mathrm{~m}$ and a wing aspect ratio of 5.7. The design launch mass is $141 \mathrm{~kg}$. The M4 is powered by an Aerojet reaction control bi-propellant thruster, typically as used to manoeuvre satellites.

Materials of construction were selected to meet the requirements of the COSPAR Planetary Protection Policy.

Because of the high risk associated with such a mission, an Earth Drop Test Vehicle was designed in parallel. This represents a $65 \%$ scaled version of the MARS vehicle, designed to be released from an Earth high altitude balloon, to emulate release and deployment in the Martian atmosphere.

\subsection{THE E5 SUPERSONIC BUSINESS JET [7]}

It would require considerable political will to embark on a new large SST aircraft programme. Major airframe manufacturers would need to commit significant resources to the project. With manufacturers currently committed to either large or environmentally friendly projects, it may be some time before large high speed transport comes to the fore. However it is believed that a significant market may exist for a Supersonic Business Jet. This goal could be a feasible venture for an airframe manufacturer.

Such an aircraft would be required to carry corporate executives, celebrities and VIPs anywhere in the world in half the time of current business jets and under a third of the time door to door. With the retirement of the Concorde SST airliner in 2003, very fast intercontinental travel ceased to be available for the public. A supersonic business jet aims to fill this void and expand access to supersonic travel in all corners of the globe. Such an aircraft, designated E5 is shown on Figure 8.

Key to the success of this design is the reduction of the sonic boom characteristics to enable supersonic flight over land, and fuel efficiency to enable such ranges as transpacific flight. In delivering these goals, the E-5 will not lose sight of the expectations of the targeted clientele and will provide all the luxury, looks and comfort expected from a small business jet.

The aircraft has been designed to the airworthiness requirements of EASA CS25 and TSS standards where 
applicable. The design life of the airframe is 20 years and 14,000 flying hours.

The aircraft has been designed to carry 6 passengers plus 2 crew at a cruise speed of M1.8 at $60,000 \mathrm{ft}$ altitude over a range of up to $5700 \mathrm{~nm}$. The MTOW is 45.5 tonne.

The aircraft is powered by two under wing Eurojet EJ200 derivative engines. The overall length is $43.6 \mathrm{~m}$ with a wing span of $16 \mathrm{~m}$. The maximum fuselage diameter is $2.18 \mathrm{~m}$.

The wing and fuselage are constructed of carbon composite material so as to minimise weight and sonic boom pressure levels.

The E5 contains two novel features. To achieve the range required, a hybrid laminar flow system was designed to help reduce the drag on the aircraft. This system uses suction over $18 \%$ of the chord to suppress the dominant modes of boundary layer separation.

The second novel feature is the use of a synthetic vision system. The forward fuselage does not contain cockpit windows because of sonic boom considerations. To provide the pilot with all the information and cues that he needs to safely fly the aircraft, a Synthetic-Enhanced Vision System (SEVS) was designed. This vision system is displayed using a helmet mounted display compatible with the glass cockpit layout. The system uses four infrared cameras located in the nose, as well as a computer generated view. SEVS is an example of new technology that can be explored in detail through a Group Design Project.

The E5 project was also unique in that Virtual reality had been used as part of the design process. For the first time we were able to have a virtual reality tour of the cabin and cockpit interior. For the cockpit this was particularly important in that such a tour was used to obtain pilot opinion of the layout.

\subsection{CONCLUSIONS}

The Group Design Project provides a major opportunity for the students to apply and develop their acquired knowledge and skills to solve difficult engineering design problems. The project allows the student to develop originality in the application of their knowledge and skills. Transferable skills such as team working, planning and managing their work effectively in a team environment, and presenting their work both orally and in writing to a variety of audiences are all strongly developed by this component of the course.

It is very important to emphasise that the Group Project focuses on the detail design because it is at the detailed design level that all the design problems and challenges lie. This is what makes the Group Design Project so unique in providing the student with the qualities and skills necessary for employment in a real world industrial context.

The output from a typical group design project is shown on Fig 9. The unique and extensive nature of the project is illustrated by the fact that each year a typical group design project will involve some 34,000 man hours of work, resulting in approx 27 GB of computer data, 6,600 pages of text and approximately 60 engineering drawings.

\subsection{FUTURE COURSE DEVELOPMENTS}

The Aerospace Vehicle Design MSc is currently undergoing several new exciting developments for academic year 2006 - 2007.

\subsection{AVIONIC SYSTEMS DESIGN}

A new Avionic Systems Design Option will be introduced, aimed at 
students who wish to specialise in Avionic Systems Design, analysis, development, test and airframe integration. Lecture modules available include

- Navigation Systems

- Airborne Instrumentation and Systems Integration

- Software Engineering

- Radio Systems

- The Cockpit Environment

- Air Traffic Control

- Fault Tolerant Avionics Design

- System Development and Life Cycle Model

- Reliability, Safety Assessment and Certification

The Avionic students will also participate in the same group design project thus bringing a much higher level of detailed Avionic System Design to the group project aircraft.

\subsection{GROUP DESIGN PROJECT DISTANCE LEARNING}

The Aerospace Vehicle Design MSc will now be offered at Dubai University, as part of a new agreement reached between Cranfield University and the Dubai Aerospace Enterprise (DAE). Plans are currently underway to run the group design project jointly between Cranfield students and Dubai students via extensive video conferencing facilities. This will build upon the Cranfield experience gained in running similar projects with Embraer in Brazil.

It is important to emphasise that video conferencing a group design project around the world will simulate for the students the international aspect of current industry projects, where design organisations from many different countries are involved in the design of an aircraft. This will further enhance the authenticity of the virtual industrial environment.

\subsection{VIRTUAL REALITY (VR)}

It is also intended to build upon the experience gained from the E5 supersonic business jet group design project, to use VR more as a design tool. As well as using VR for cockpit and cabin design, it will also now be used for designing for maintainability. It is currently very difficult to design aircraft for good maintainability. It is intended to research the use of CAD and VR to predict maintenance at an early design stage.

\subsection{PRODUCT $\quad$ DATA MANAGEMENT (PDM)}

Extensive use of CAD (CATIA) is now a regular feature of the group design project. Typically $27 \mathrm{~GB}$ of computer data are generated each year for each project. A CAD coordination student team is set up to look after the configuration control of all such data. But more recently this has become a very significant task. Hence PDM software is currently being explored in an attempt to control the computer data generated in a more efficient way.

\section{ACKNOWLEDGEMENT.}

The author wishes to thank Prof. D. Howe for some of the historical information provided in this paper.

\section{NOTE}

This paper is an expansion of a presentation given by the author at the $7^{\text {th }}$ European Workshop for Aircraft Design Education (EWADE) held in Toulouse on $19^{\text {th }}$ to $21^{\text {st }}$ October 2005. 


\section{REFERENCES}

1. Flight Magazine, The College of Aeronautics July 25th 1946, p81

2. Howe, D. A Brief History of the College of Aeronautics with special reference to the Department of Aircraft Design 1946-1992. Private communication with the author, 2003.

3. Savin-Baden, M. Constructing Problem-Based Learning Curricula. Short Course Notes, 2005.

4. Smith, H. F02 Civil Freight Aircraft Project Executive Summary, 2003.

5. Stocking, $\mathbf{P}$ and Levy, S. U3 Joint Services Unmanned Combat Air System Project Executive Summary, 2004.

6. Stocking, $\mathbf{P}$ and Sumner, L. M4 MARS Atmospheric Flight Vehicle Project Executive Summary, 2005.

7. Stocking, $\mathbf{P}$ and Morency, R. E5 Supersonic Business Jet Project Executive Summary, 2006. 


\section{LIST OF ABBREVIATIONS}

$\begin{array}{ll}\text { AVD } & \text { Aerospace Vehicle Design } \\ \text { MSc } & \text { Master of Science } \\ \text { PBL } & \text { Problem Based Learning } \\ \text { ESDU } & \text { Engineering Sciences Data Unit } \\ \text { MMPDS } & \text { Metallic Materials Property Development and Standardisation } \\ \text { DEF-STAN } & \text { Defence Standards } \\ \text { MIL-STD } & \text { Military Standards } \\ \text { JAR } & \text { Joint Airworthiness Requirements } \\ \text { CS } & \text { Certification Specifications } \\ \text { CAD } & \text { Computer Aided Design } \\ \text { MTOW } & \text { Maximum Take Off Weight } \\ \text { UTA } & \text { Uninhabited Tactical Aircraft } \\ \text { UCAV } & \text { Unmanned Combat Air Vehicle } \\ \text { SEAD } & \text { Suppression of Enemy Air Defences } \\ \text { LCC } & \text { Life Cycle Costs } \\ \text { FOAS } & \text { Future Offensive Air System } \\ \text { JSF } & \text { Joint Strike Fighter } \\ \text { ICE } & \text { Inlaid Control Effectors } \\ \text { SST } & \text { Super Sonic Transport } \\ \text { EASA } & \text { European Aviation Safety Agency } \\ \text { SEVS } & \text { Synthetically Enhanced Vision System } \\ \text { GB } & \text { Giga Byte } \\ \text { DAE } & \text { Dubai Aerospace Enterprise } \\ \text { VR } & \text { Virtual Reality } \\ \text { PDM } & \text { Product Data Management } \\ & \end{array}$

\section{LIST OF FIGURES}

These are available in a separate WORD document file. 